\title{
A!
}

This is an electronic reprint of the original article.

This reprint may differ from the original in pagination and typographic detail.

Rämä, Minna; Jokilaakso, Ari; Klemettinen, Lassi; Salminen, Justin; Taskinen, Pekka

\section{Experimental Investigation of Pyrometallurgical Treatment of Zinc Residue}

\section{Published in:}

Extraction 2018

DOI:

10.1007/978-3-319-95022-8_79

Published: 01/01/2018

Document Version

Peer reviewed version

Published under the following license:

Unspecified

Please cite the original version:

Rämä, M., Jokilaakso, A., Klemettinen, L., Salminen, J., \& Taskinen, P. (2018). Experimental Investigation of Pyrometallurgical Treatment of Zinc Residue. In B. Davis, M. Moats, \& S. Wang (Eds.), Extraction 2018:

Proceedings of the First Global Conference on Extractive Metallurgy (pp. 981-992). (The Minerals, Metals \& Materials Series). SPRINGER. https://doi.org/10.1007/978-3-319-95022-8_79

This material is protected by copyright and other intellectual property rights, and duplication or sale of all or part of any of the repository collections is not permitted, except that material may be duplicated by you for your research use or educational purposes in electronic or print form. You must obtain permission for any other use. Electronic or print copies may not be offered, whether for sale or otherwise to anyone who is not an authorised user. 


\title{
Experimental investigation of pyrometallurgical treatment of zinc residue
}

\author{
Minna Rämä ${ }^{1}$, Ari Jokilaakso ${ }^{1}$, Lassi Klemettinen ${ }^{1}$, Justin Salminen², Pekka Taskinen ${ }^{1}$ \\ ${ }^{1}$ Aalto University, School of Chemical Engineering, Dept. Chemical and Metallurgical Engineering, P.O. Box \\ 16200, 00076 Aalto (Finland) \\ ${ }^{2}$ Boliden Kokkola Oy, P.O. Box 26, 67101 Kokkola (Finland) \\ Tel: MR +358505264301, AJ +358503138885, LK +358442149569, JS +358406527850, PT +358405017411 \\ E-mail:minna.rama@aalto.fi, ari.jokilaakso@aalto.fi, lassi.klemettinen@aalto.fi, \\ justin.salminen@boliden.com, pekka.taskinen@aalto.fi
}

\begin{abstract}
Iron containing leach residues like jarosite and goethite from electrolytic zinc production contain many valuable metals and harmful substances. These metals and substances should be removed in order to obtain an acceptable, stable and reusable product, and maximize economic feasibility as well as minimize environmental footprint. In this work, the processing of jarosite leach residue was studied in laboratory scale experiments under oxidizing and reducing conditions at high temperatures. First, the pretreated material was melted and oxidized to produce a melt of metal oxides. Second, the oxide melt was reduced in $\mathrm{CO}-\mathrm{CO}_{2}$ atmosphere. Target after the reduction step was to obtain a clean slag and a liquid metal or speiss phase that collects the valuable metals, such as silver. The kinetics of the thermal processing were studied for determining optimal times and conditions for the aforementioned process steps. The preliminary results show that the process is thermodynamically feasible, and the desired phases can be obtained in the experimental conditions investigated.
\end{abstract}

Keywords: Jarosite smelting, Thermal processing, Circular economy, Slag valorization

\section{Introduction}

Large amounts of iron rich sludges are landfilled in residue areas close to production plants. While in some countries landfilling is allowed, there is a trend towards thermal processing of these wastes in several production sites. Currently, $85 \%$ of zinc is produced worldwide by means of Roasting-Leaching-Electrowinning (RLE) process [1]. The leaching step of the RLE process generates 0.5 to 0.9 tonnes of jarosite leach residue for every tonne of zinc produced as the iron level of the leach solution is controlled by precipitation [2, 3]. The chemical formula of jarosite is $\mathrm{MFe}_{3}\left(\mathrm{SO}_{4}\right)_{2}(\mathrm{OH})_{6}$, where $M$ represents either $\mathrm{Na}^{+}, \mathrm{K}^{+}, \mathrm{Li}^{+}, \mathrm{NH}_{4}^{+}, \mathrm{H}_{3} \mathrm{O}^{+}, \mathrm{Ag}^{+}$, or $^{1 / 2} \mathrm{~Pb}^{2+}$ [4]. Jarosite, goethite, and other leach residues contain, in addition, several potentially recoverable metals in dilute concentrations, originating from the process and feed. The trace metals found in the iron rich sludges can be either critical (In, Ga, Ge, and Sb), precious and valuable (Ag and $\mathrm{Au}$ ), heavy metals of concern (Cd, $\mathrm{As}$, and $\mathrm{Hg}$ ), or unrecovered base metals $(\mathrm{Zn}, \mathrm{Cu}$, and $\mathrm{Pb})$. Due to the aforementioned heavy metals, iron rich sludges such as jarosite and goethite residues are classified as hazardous waste and, therefore, cannot be utilized as such. [3, 5]

Suitable technologies for further treatment of the residues are currently being studied and new residue treatment plants have been built or are under construction. Nevertheless, in many cases the residues are still stabilized and disposed into open tailing dumps. This prevents the valorization of metal values that are consequently not recycled. Because of the aim towards circular economy and more efficient use of natural resources, these landfilled metal-containing residues could be important raw material sources. [2, 6] Asides from circular economy and recovery of the valuable metals, other incentives for developing new methods for iron rich residue processing include the decreasing availability of land for jarosite storage, and the possibility of using the obtained clean slag in road building and other construction material applications. Currently, pyrometallurgical treatment is the most viable processing method, as it enables the production of clean, environmentally friendly slag and the recovery of metal values. [2,7] As one downside, carbon is used as a reducing agent to volatilize metals out of the slag, which will increase $\mathrm{CO}_{2}$ emissions. 
The thermal processing of jarosite leach residue has been investigated with a computational thermodynamic model [8], which was created with MTDATA software [9] and MTOX database [10]. Based on this model and earlier studies $[8,11,12]$, the process is divided into two functional steps, which oxidize, decompose, and then reduce the material. In the oxidizing step, the material is melted under oxidizing conditions to decompose the material, e.g. to release OH-groups and sulfates and to produce an oxide melt. In the next step, the melt is reduced so that a clean slag is produced, as the volatile elements are removed to the off-gas and a liquid metal alloy is formed. This metal phase acts as the collector for various low-concentration metals (for example As, $\mathrm{Sb}$, and Ag). [2] Only the reduction step was included in the thermodynamic model, but the results were promising [8]. The aim of this work is to experimentally verify the modeling results, as well as include the oxidation step into the process.

Laboratory-scale high-temperature $\left(1350-1400{ }^{\circ} \mathrm{C}\right)$ experiments were conducted to investigate how to convert jarosite leach residue into a product that could be applied for construction purposes $(\mathrm{Pb}<0.03 \mathrm{wt}-\%$ and $\mathrm{Zn}<1$ wt- $\%$ ), and how to recover the valuable metals from the residue. The aim was to determine the optimal processing conditions and parameters (processing time, temperature, gas flows) for both stages of the treatment. The experimental work was conducted with industrial jarosite samples. The microstructure and phase composition of the samples were analyzed with a scanning electron microscope equipped with an energy dispersive spectrometer (SEM-EDS). The chemical composition of the bulk samples was determined with inductively coupled plasma optical emission spectroscopy (ICP-OES).

\section{Experimental}

\section{Equipment}

High-temperature $\left(1350-1400^{\circ} \mathrm{C}\right)$ oxidation and reduction experiments were performed in a vertical tube furnace Lenton LTF 16/-/450 (Lenton, UK) equipped with an alumina working tube (Impervious pure alumina, 45/38 mm OD/ID). The temperature was monitored with a calibrated Pt/Pt10Rh thermocouple (Johnson-Matthey, UK, uncertainty $\pm 3^{\circ} \mathrm{C}$ ) inside an alumina sheath, connected to Keithley multimeters (models 2000 and 2010, Keithley, USA). The gases used in the pre-treatments and experiments (air: $80 \% \mathrm{~N}_{2} 5.0 \& 20 \% \mathrm{O}_{2} 5.0, \mathrm{O}_{2}:$ 5.0, argon: 5.0, $\mathrm{CO}: 3.7, \mathrm{CO}_{2}$ : 5.3, all from AGA Linde, Finland) were injected from the top of the furnace. The gas flows were controlled either with rotameters (air, $\mathrm{O}_{2}$, argon; Kytola Instruments, Finland) or mass flow controllers ( $\mathrm{CO}, \mathrm{CO}_{2}$; Aalborg DFC26, USA). Fig. 1 shows a schematic illustration of the experimental equipment.

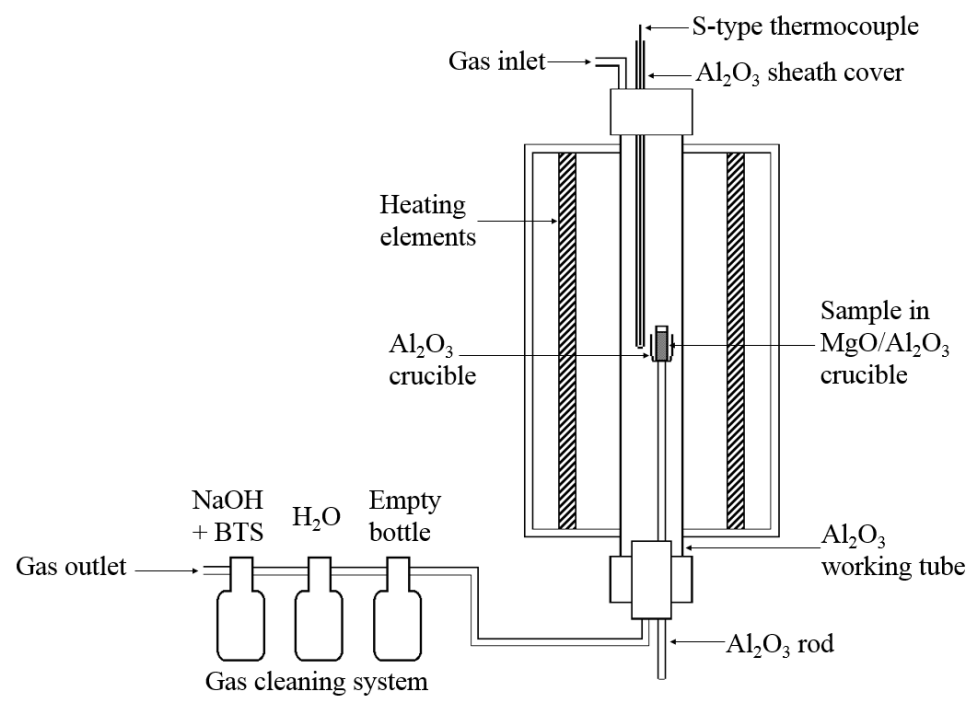

Fig. 1 A cross-section of the experimental equipment.

Dense $\mathrm{MgO}$ crucibles (SC10030, 20/75 mm ID/H, Tateho Ozark Technical Ceramics, USA) were used in the pretreatments and first oxidation experiments with large samples. Alumina crucibles (Frialit AL23, 8/15 mm ID/H, Friatec AG, Germany) were used in the experiments with smaller samples. The sample was introduced into the hot zone of the furnace by lifting up the alumina rod that entered the furnace through a leak-proof plug at the bottom of the furnace (Fig. 1). 
A gas cleaning system was connected to the furnace gas outlet to ensure the off-gases and volatilized elements to be safely neutralized or recovered. To enhance the gas outflow from the furnace, an underpressure pump (LabVac LVH40, Piab, Sweden) was used. The first bottle of the system was empty and used to prevent the escape of the liquids from the cleaning system into the furnace in case of a blockage in the gas train. The second bottle contained $\mathrm{H}_{2} \mathrm{O}$ and the third a $\mathrm{NaOH}$ solution $(6.5 \mathrm{M}, 98 \% \mathrm{NaOH}$ pellets from J.T.Baker, USA) with a BTS indicator (Bromothymol blue, $\mathrm{C}_{27} \mathrm{H}_{28} \mathrm{Br}_{2} \mathrm{O}_{5} \mathrm{~S}$, Sigma-Aldrich, USA) to indicate the point, where $\mathrm{NaOH}$ was consumed from the scrubber solution.

Test material, drying and pre-treating

Experiments were conducted with industrial jarosite residue samples. Based on chemical analysis (ICP-OES), the material contained initially circa $15 \mathrm{wt}-\%$ of iron, $4 \mathrm{wt}-\%$ of zinc and $3 \mathrm{wt}-\%$ of lead. However, the composition may vary, as the residue is somewhat heterogeneous in nature. Prior to the experiments, the moisture content was decreased by drying the material at $80^{\circ} \mathrm{C}$ for $18 \mathrm{~h}$. The dried material was manually ground in a mortar with pestle to obtain a more homogenous particle size and sample composition.

The material was pre-treated at $700{ }^{\circ} \mathrm{C}$ for $15 \mathrm{~min}$ under air atmosphere $(65 \mathrm{~mL} / \mathrm{min})$ to thermally decompose the material and, thus, release the $\mathrm{OH}$-groups and sulfates. The crucible containing the test material was gradually elevated to the hot zone of the furnace to prevent cracking of the crucible, and held in the hot zone for $15 \mathrm{~min}$. After the treatment, the crucible was lowered to the colder section of the furnace for cooling. Several pre-treated batches were mixed together prior to the actual experiments. Each pre-treated batch was weighed before and after pre-treating to verify that the mass loss was sufficient compared to the TGA (Thermogravimetric Analysis) results obtained in a previous study [8].

\section{Oxidation and reduction experiments}

As mentioned earlier, the thermodynamic model used for estimating the behavior of jarosite residue during thermal processing included only the reduction step [8]. However, the results obtained by this model were used as the first iteration for the parameters in the oxidation step as well. Initial oxidation experiments $\mathrm{O} 1-\mathrm{O} 5$ were conducted at $1350^{\circ} \mathrm{C}$ under air atmosphere $(65 \mathrm{~mL} / \mathrm{min})$ with different oxidation times. To promote the oxidation, the flow rate of air was quadrupled for the next experiments (O6-O7). The sample masses in these seven oxidation experiments (Table 1: Oxidation I) were around $18 \mathrm{~g}$ and the samples were held in $\mathrm{MgO}$ crucibles during the experiments.

SEM-EDS and ICP-OES analyses were performed for the samples O1-O7. The analyses showed that the material was not completely molten at the selected experimental temperature and, therefore, the advancement of oxidation reaction was insufficient. Consequently, the removal of excess sulfur did not occur sufficiently.

Based on the results of the first oxidation experiments, the parameters were modified to melt the material completely and to reach the target regarding sulfur concentration. For the second set of the oxidation experiments (Table 1: Oxidation II), the temperature was raised to $1400{ }^{\circ} \mathrm{C}$, the sample size was reduced to about $0.5 \mathrm{~g}$ and air as oxidizing gas was replaced by $\mathrm{O}_{2}(65 \mathrm{~mL} / \mathrm{min})$. Small $\mathrm{Al}_{2} \mathrm{O}_{3}$ crucibles were utilized in the second set of the oxidation experiments due to their availability. The change in the crucible material should not affect the fundamental behavior of the material during the oxidation process. Only SEM-EDS analyses were performed for these samples due to the small sample size, and based on the results, 60 minutes was enough to oxidize the small sample.

A third set of oxidation experiments (Table 1: Oxidation III) was conducted in $\mathrm{MgO}$ crucibles with a sample mass of $8 \mathrm{~g}$ for enabling the chemical analyses to be performed in addition to the SEM-EDS analysis. The experimental parameters were otherwise the same as in Oxidation II series, but the oxidation times were 30 and 60 minutes. The aim was to investigate if the parameters optimized during Oxidation II experiments also work for larger samples.

The reduction experiments included both oxidizing and reducing process steps. The parameters used in the oxidation step were selected based on the oxidation experiments described above. The material (sample mass 0.5 g) was oxidized for $60 \mathrm{~min}$ under $\mathrm{O}_{2}$ atmosphere $(65 \mathrm{~mL} / \mathrm{min})$ in $\mathrm{Al}_{2} \mathrm{O}_{3}$ crucibles at $1400{ }^{\circ} \mathrm{C}$. The reduction was performed under $\mathrm{CO}-\mathrm{CO}_{2}$ atmosphere $(50: 50,260 \mathrm{~mL} / \mathrm{min}$ in total) with different reduction times (see Table 1). 
Table 1 Experimental parameters used in oxidation and reduction experiments.

\begin{tabular}{|c|c|c|c|c|c|c|}
\hline $\begin{array}{l}\text { Sample } \\
\text { ID }\end{array}$ & $\begin{array}{l}\text { Sample } \\
\text { size }(g)\end{array}$ & $\begin{array}{c}\text { Temperature } \\
\left({ }^{\circ} \mathrm{C}\right)\end{array}$ & $\begin{array}{l}\text { Oxidation } \\
\text { time (min) }\end{array}$ & $\begin{array}{l}\text { Oxidizing gas / flow } \\
\text { rate }(\mathrm{mL} / \mathrm{min})\end{array}$ & $\begin{array}{l}\text { Reduction } \\
\text { time (min) }\end{array}$ & $\begin{array}{l}\text { Reducing gas / flow } \\
\text { rate }(\mathrm{mL} / \mathrm{min})\end{array}$ \\
\hline \multicolumn{7}{|c|}{ Oxidation I } \\
\hline$\overline{\mathrm{O} 1}$ & 18 & 1350 & 5 & air / 65 & - & - \\
\hline $\mathrm{O} 2$ & 18 & 1350 & 15 & air / 65 & - & - \\
\hline $\mathrm{O} 3$ & 18 & 1350 & 30 & air / 65 & - & - \\
\hline $\mathrm{O} 4$ & 18 & 1350 & 60 & air / 65 & - & - \\
\hline O5 & 18 & 1350 & 120 & air / 65 & - & - \\
\hline O6 & 18 & 1350 & 60 & air / 260 & - & - \\
\hline $\mathrm{O} 7$ & 18 & 1350 & 120 & air / 260 & - & - \\
\hline \multicolumn{7}{|c|}{ Oxidation II } \\
\hline O8 & 0.5 & 1400 & 60 & $\mathrm{O}_{2} / 65$ & - & - \\
\hline O9 & 0.5 & 1400 & 120 & $\mathrm{O}_{2} / 65$ & - & - \\
\hline \multicolumn{7}{|c|}{ Oxidation III } \\
\hline $\mathrm{O} 10$ & 8 & 1400 & 30 & $\mathrm{O}_{2} / 65$ & - & - \\
\hline O11 & 8 & 1400 & 60 & $\mathrm{O}_{2} / 65$ & - & - \\
\hline \multicolumn{7}{|c|}{ Oxidation + Reduction } \\
\hline R1 & 0.5 & 1400 & 60 & $\mathrm{O}_{2} / 65$ & 30 & $\mathrm{CO}-\mathrm{CO}_{2}(50: 50) / 260$ \\
\hline $\mathrm{R} 2$ & 0.5 & 1400 & 60 & $\mathrm{O}_{2} / 65$ & 60 & $\mathrm{CO}-\mathrm{CO}_{2}(50: 50) / 260$ \\
\hline R3 & 0.5 & 1400 & 60 & $\mathrm{O}_{2} / 65$ & 120 & $\mathrm{CO}-\mathrm{CO}_{2}(50: 50) / 260$ \\
\hline
\end{tabular}

Oxidation and reduction experiments were conducted by gradually elevating the sample-containing crucible to the hot zone of the furnace under inert atmosphere (argon). After the sample reached the experimental temperature, the gas was changed to air or oxygen. In the oxidation experiments, the conditions were changed back to inert after the oxidation, and the sample was lowered to the colder section of the furnace for cooling. In the reduction experiments, the conditions were changed to reducing $\left(\mathrm{CO}-\mathrm{CO}_{2}\right)$ after the oxidation, without cooling the sample in between. After the reduction, the crucible was lowered to the colder section for cooling under inert conditions.

\section{$\underline{\text { Sample analysis }}$}

The samples were cast in epoxy resin and prepared for SEM-EDS analysis with traditional metallographic methods. After polishing, the samples were cleaned in an ultrasonic bath for 15 minutes in ethanol. A thin carbon layer was evaporated on the sample surfaces with a sputtering device (Leica EM SCD050, Leica microsystems, Germany) to ensure sufficient electrical conductivity on the surface during the analysis.

The microstructure and phase composition of all samples were examined with SEM (Zeiss LEO $1450 \mathrm{~W}$-filament SEM, Carl Zeiss AG, Germany) equipped with an EDS (Oxford X-Max $50 \mathrm{~mm}^{2}$, Oxford Instruments, United Kingdom). The acceleration voltage was set to $15 \mathrm{kV}$, and the standards employed for the main elements were albite ( $\mathrm{Al}$ and $\mathrm{Na}, \mathrm{K}$-series peaks), barite (Ba, L-series), apatite (Ca, K-series), hematite (Fe, K-series), sanidine (K, K-series), olivine ( $\mathrm{Mg}$ and $\mathrm{O}, \mathrm{K}$-series), quartz ( $\mathrm{Si}, \mathrm{K}$-series), zinc sulfide ( $\mathrm{Zn}, \mathrm{K}$-series), copper (Cu, $\mathrm{K}$ series), lead ( $\mathrm{Pb}, \mathrm{M}$-series), and pyrite ( $\mathrm{S}, \mathrm{K}$-series). XPP-ZAF matrix correction procedure was applied for the raw data processing [13].

For determining the bulk composition of the samples, chemical analyses were performed using ICP-OES apparatus. These analyses were only performed for the samples of 8 or $18 \mathrm{~g}$ size, as the amount of material in the smaller crucibles was not sufficient for this analysis method.

\section{Results and discussion}

Only small parts of the material at the bottom and edges of the crucibles melted during the treatment conducted at $1350{ }^{\circ} \mathrm{C}$ (Oxidation I). SEM-EDS analyses were performed for parts of the molten sections. Fig. 2 a-b show the microstructures of samples $\mathrm{O} 6$ and $\mathrm{O} 7$. White precipitates of different sizes are clearly visible in the slag matrix. These precipitates contain mainly sulfur, iron, zinc and lead. Based on the SEM-EDS analyses, the average sulfur content in the molten slag phase was approximately $0.7 \mathrm{wt}-\%$ in each sample. However, based on the chemical bulk composition analyses, the overall sulfur content was reduced only $27 \%$ compared to the dried 
material. Quadrupling the flow rate of air did not result in more efficient sulfur removal. Therefore, the experimental parameters had to be modified, since the removal of sulfur is important for the stability of the slag product.

Table 2 Bulk compositions of the samples (in wt-\%), based on the chemical analysis results. Trace elements have been omitted from the results, and oxygen concentrations were not determined.

\begin{tabular}{cccccccccccc}
\hline Sample ID & $\mathrm{Ag}$ & $\mathrm{Al}$ & $\mathrm{Ca}$ & $\mathrm{Cu}$ & $\mathrm{Fe}$ & $\mathrm{K}$ & $\mathrm{Mg}$ & $\mathrm{Na}$ & $\mathrm{Pb}$ & $\mathrm{Si}$ & $\mathrm{Zn}$ \\
\hline Pre-treated & 0.02 & 0.95 & 4.20 & 0.28 & 26.40 & 0.45 & 0.23 & 2.20 & 5.30 & 3.60 & 5.90 \\
\hline \multicolumn{2}{l}{ Oxidation I } & & & & & & & & & & \\
\hline O1 & 0.04 & 0.38 & 1.40 & 0.36 & 38.20 & 0.77 & 0.22 & 2.70 & 7.00 & 0.32 & 8.60 \\
O2 & 0.03 & 0.50 & 1.80 & 0.35 & 37.90 & 0.97 & 0.69 & 2.80 & 6.40 & 0.34 & 8.60 \\
O3 & 0.04 & 0.26 & 1.20 & 0.37 & 39.00 & 0.93 & 0.46 & 2.80 & 5.80 & 0.12 & 8.40 \\
O4 & 0.04 & 0.29 & 1.30 & 0.37 & 40.70 & 0.89 & 0.56 & 2.90 & 5.20 & 0.19 & 8.50 \\
O5 & 0.04 & 0.22 & 1.10 & 0.40 & 42.10 & 0.73 & 0.61 & 2.80 & 3.50 & 0.10 & 8.20 \\
O6 & 0.04 & 0.21 & 1.30 & 0.43 & 39.20 & 0.58 & 0.53 & 2.40 & 5.10 & 0.49 & 8.50 \\
O7 & 0.04 & 0.06 & 1.30 & 0.50 & 43.40 & 0.63 & 0.26 & 2.60 & 3.80 & 0.41 & 8.50 \\
\hline \multicolumn{2}{l}{ Oxidation III } & & & & & & & & & & \\
\hline O10 & 0.04 & 0.67 & 3.10 & 0.44 & 38.70 & 0.60 & 1.90 & 2.70 & 2.30 & 2.60 & 7.10 \\
O11 & 0.02 & 1.30 & 5.70 & 0.39 & 29.70 & 0.53 & 4.50 & 3.00 & 0.11 & 5.90 & 4.20 \\
\hline
\end{tabular}

The insufficient oxidation of samples $\mathrm{O} 1-\mathrm{O} 7$ can be attributed to the incomplete melting of the material. The formation of the melt is essential for the oxidation process, as mass transfer is markedly faster and more efficient in liquid state compared to solid state. Reasons for the inconsistent results between the thermodynamic model and the experiments may include the heterogeneities in the jarosite residue composition, and the different process step in the model compared to the experiments (reduction vs. oxidation).
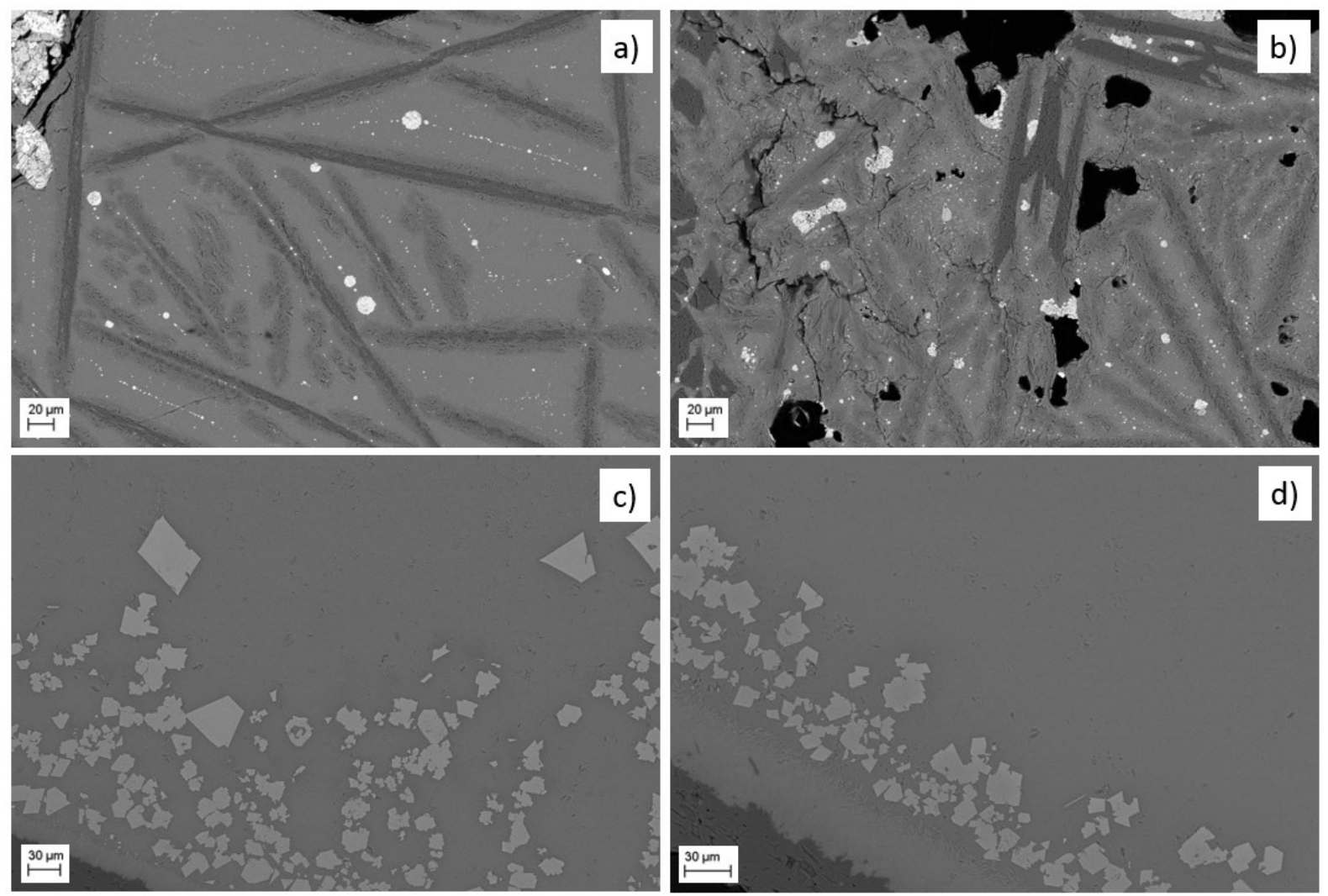

Fig. 2 Microstructures of oxidation experiments a) O6 b) O7 c) 08 and d) O9. White spots in a) and b) are precipitates containing sulfur, iron, zinc and lead, which were not oxidized during the treatment. In c) and d), the obtained phases are liquid slag (darker matrix) and solid alumina-rich spinels (lighter phase areas). Some alumina-poor spinels were also formed.

Based on the results of experiments $\mathrm{O} 1-\mathrm{O} 7$, the temperature was raised to $1400^{\circ} \mathrm{C}$ and the oxidizing gas changed from air to oxygen. The sample size was also considerably decreased for studying the process in a very small 
scale. SEM images of two experiments conducted at $1400{ }^{\circ} \mathrm{C}(\mathrm{O} 8$ and O9) are shown in Fig. 2 c-d. The aforementioned parameter changes resulted in complete melting of the material. SEM-EDS analyses showed that sulfur was successfully removed from the material already after 60 minutes $(0.0 \mathrm{wt}-\%$ in each phase according to EDS). Three phases; liquid slag (dark areas in Fig. 2 c-d), solid alumina-rich spinels (light areas in Fig. 2 c-d) surrounded by the liquid slag, and some alumina-poor spinels, were clearly distinguished. Table 3 shows the average compositions of these phases. The concentration of zinc in the individual spinel grains within one sample exhibited in some cases deviations of up to $50 \%$ from the average value.

Table 3 Average compositions of the slag and spinel phases in the small oxidation and reduction samples (in wt-\%), obtained with SEM-EDS.

\begin{tabular}{|c|c|c|c|c|c|c|c|c|c|c|c|c|}
\hline Sample ID & $\mathrm{Al}$ & $\mathrm{Ba}$ & $\mathrm{Ca}$ & $\mathrm{Cu}$ & $\mathrm{Fe}$ & $\mathrm{K}$ & $\mathrm{Mg}$ & $\mathrm{Na}$ & $\mathrm{O}$ & $\mathrm{Pb}$ & $\mathrm{Si}$ & $\mathrm{Zn}$ \\
\hline \multicolumn{13}{|l|}{ O8 } \\
\hline liquid slag & 14.7 & 2.7 & 11.7 & 0.1 & 9.8 & 0.7 & 0.2 & 5.1 & 41.5 & 0.4 & 12.6 & 0.5 \\
\hline Al-rich spinel & 18.3 & & & 0.0 & 34.9 & & 2.4 & & 34.3 & & & 10.1 \\
\hline Al-poor spinel & 7.0 & & 0.2 & 0.4 & 56.8 & & & & 29.7 & & & 5.8 \\
\hline \multicolumn{13}{|l|}{ O9 } \\
\hline liquid slag & 15.5 & 2.4 & 11.5 & 0.0 & 9.0 & 0.7 & 0.2 & 5.0 & 42.5 & 0.3 & 12.4 & 0.5 \\
\hline Al-rich spinel & 20.1 & & & 0.2 & 29.7 & & 3.4 & & 36.5 & & & 10.1 \\
\hline Al-poor spinel & 6.5 & & 0.3 & 0.8 & 57.5 & & & & 30.4 & & & 4.5 \\
\hline \multicolumn{13}{|l|}{$\mathrm{R} 1$} \\
\hline liquid slag & 12.5 & 2.7 & 11.3 & 0.0 & 14.2 & 0.8 & 0.1 & 5.5 & 40.4 & 0.0 & 12.3 & 0.2 \\
\hline solid spinel & 26.7 & & & 0.0 & 28.5 & & 1.5 & & 38.2 & & & 5.2 \\
\hline \multicolumn{13}{|l|}{ R2 } \\
\hline liquid slag & 13.5 & 3.1 & 12.2 & 0.0 & 10.1 & 0.9 & 0.1 & 6.0 & 40.7 & 0.0 & 13.5 & 0.1 \\
\hline solid spinel & 28.5 & & & 0.0 & 26.7 & & 1.6 & & 37.5 & & & 5.6 \\
\hline \multicolumn{13}{|l|}{ R3 } \\
\hline liquid slag & 14.5 & 2.8 & 12.5 & 0.0 & 7.5 & 0.8 & 0.1 & 5.5 & 42.6 & 0.0 & 13.6 & 0.2 \\
\hline solid spinel & 28.6 & & & 0.0 & 25.6 & & 1.7 & & 38.8 & & & 5.4 \\
\hline
\end{tabular}

As the oxidation experiments performed with the small samples at $1400{ }^{\circ} \mathrm{C}$, in $\mathrm{O}_{2}$ atmosphere were successful, the same experimental parameters were employed for bigger samples as well (Oxidation III). The larger sample size enabled the chemical analyses to be performed for the samples in addition to the SEM-EDS analyses. It was observed that the material melted during the treatment, but some small sulfur-containing precipitates remained. The chemical analysis showed a $49 \%$ drop in the sulfur content compared to the dried material after 30 minutes, which indicates that this treating time is far too short for efficient sulfur removal. After 60 minutes, the sulfur content was reduced by $93 \%$, resulting in a concentration close to the targeted sulfur level $(<1 \mathrm{wt}-\%)$.

The reduction stage was only studied with the small samples. Fig. 3 a-b show the SEM images of reduction experiments R1 (30 min) and R3 (120 min). Two phases, slag and alumina-rich spinel, were distinguished. The darker grey matrix in Fig. 3 a-b is liquid slag and the lighter grey, angular grains are spinels. The compositions of these phases are shown in Table 3. In the 30 and 60-minute reduction experiments, some of the spinels had a lighter grey core. EDS analyses showed that these cores have a higher concentration of zinc compared to the spinel area surrounding the core. This type of behavior indicates that the reduction of the spinel phase obeys a shrinking core model [14]. After 120 minutes (Fig. 3 b), these zinc-rich cores have almost completely disappeared. Based on the shape of the individual spinel grains, they are not molten at $1400{ }^{\circ} \mathrm{C}$, which explains the relatively long time required for the reduction step to be completed.

As Table 3 shows, the concentration of zinc in the spinel phase is higher than the target of $<1 \mathrm{wt} \%$. However, the concentration of zinc in the liquid slag phase is very low, and in the absence of chemical bulk composition analyses, it is impossible to estimate the average concentration of zinc in the whole sample. The zinc concentration in the spinels seems to remain constant as a function of reduction time, even though the amount of zinc in the sample is most likely decreased as the reduction proceeds. The constant concentration in the spinels may be explained by the decreasing combined volume of the spinel grains with increasing time. In addition, the zinc concentration in the spinels, as shown in Table 3 , is the average value without the zinc-rich cores. 
The target for lead concentration in the sample after reduction was $<0.03 \mathrm{wt}-\%$. Based on the results shown in Table 3, the lead dissolved in the slag after oxidation was completely volatilized in the reduction step already after 30 minutes. However, as EDS is not accurate at these low concentration ranges, the actual concentration of lead must be verified from bulk chemical analyses performed for the larger reduction samples in the future.

Some small, below $20 \mu \mathrm{m}$ diameter speiss areas were also distinguished after the reduction stage (seen as small white droplets in Fig. $3 \mathrm{a}-\mathrm{b}$ ). These areas contained mainly copper, but also some arsenic, antimony and silver. It seems that the copper concentration in the initial jarosite residue is not sufficient for the formation of any larger speiss areas. The small, individual speiss droplets also seem to be attached to the spinel grains, which may hinder their settling and coalescence during the process [15].
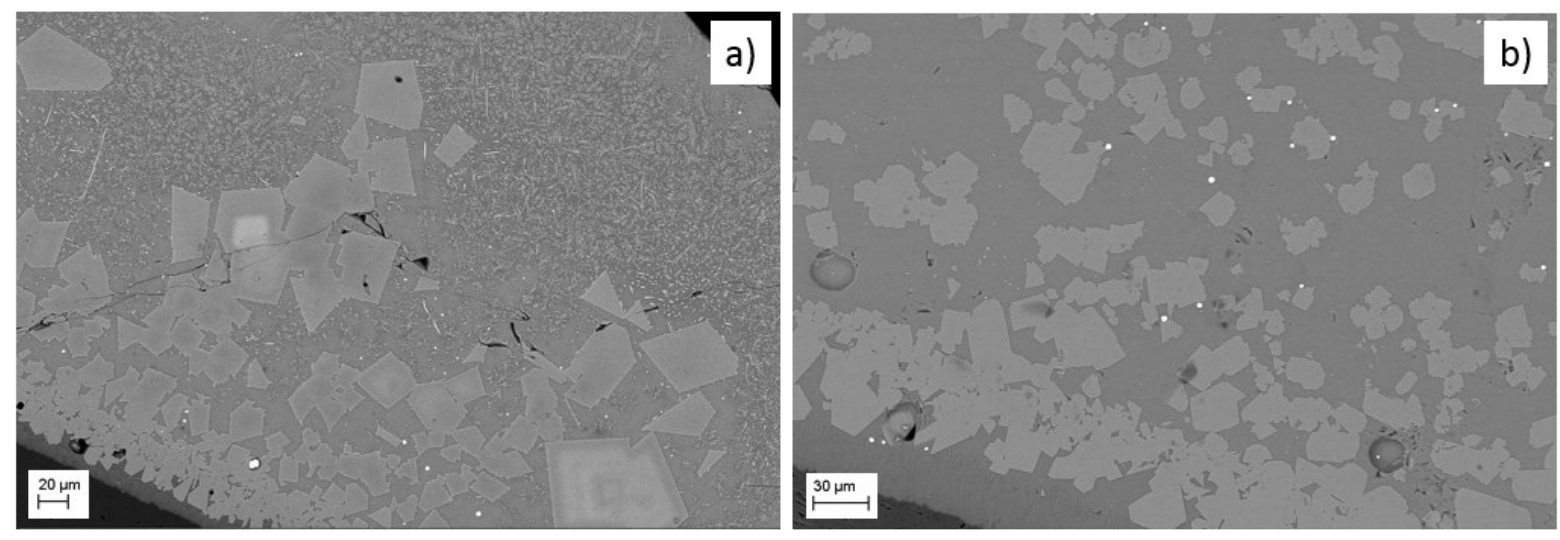

Fig. 3 Microstructures of the samples after a) $30 \mathrm{~min}$ (R1) and b) $120 \mathrm{~min}$ (R3) reduction experiments. The darker grey areas are liquid slag, and the lighter grey grains are spinels. The lighter cores in some of the spinels in a) have higher concentration of zinc compared to the surrounding spinel area, indicating a shrinking core -type behavior during the reduction stage.

\section{Conclusions}

Pyrometallurgical oxidation-reduction treatment of industrial jarosite residue was investigated in laboratory-scale high-temperature experiments, using the guidance from a thermodynamic model [8] as the first iteration. The aim was to produce a clean slag (sulfur $<1$, zinc $<1$, and lead $<0.03 \mathrm{wt}-\%$ ) that could be utilized for example in construction, and to recover the valuable metals from the residue. After a few iterations regarding process parameters, slag, solid alumina-rich spinels, and small speiss droplets were formed. The concentrations of sulfur, zinc, and lead were close to the target values.

Based on the experiments, the following conclusions can be drawn. Firstly, the rate controlling step in the oxidation stage seems to be mass transfer of $\mathrm{O}_{2}$ in the solid and molten material. Therefore, it can be concluded as well that effective oxidation requires fully molten material and, thus, a high process temperature. At $1400{ }^{\circ} \mathrm{C}$, the material is completely molten apart from the spinels, but complete oxidation and reduction still require quite long processing times. So, secondly, some kind of mixing method should be introduced into the system.

Thirdly, the experimental results obtained suggest that the theoretical considerations are valid and, therefore, it seems plausible that the process would work in practice. Consequently, the suggested pyrometallurgical processing may prove to be a viable option for producing a clean slag product from jarosite residue as well as recovering the metal values.

This research will continue for finding solutions for accelerating the mass transfer by introducing mixing or a direct flow of oxygen into the crucible, and optimizing the process parameters for larger sample sizes.

\section{Acknowledgements}

This work has been financed by TEKES nationally funded CMEco project (grant number 2116781). The authors are grateful to Samu Nurmi for performing some of the experiments. 


\section{References}

[1] Souza AD, Pina PS, Leão VA (2007) Bioleaching and chemical leaching as an integrated process in the zinc industry. Minerals Engineering 20(6):591-599

[2] Creedy S, Glinin A, Matusewicz R, Hughes S, Reuter M (2013) Outotec ${ }^{\circledR}$ Ausmelt technology for treating zinc residues. World of Metallurgy - Erzmetall 66(4):230-235

[3] Hage JLT, Schuiling RD (2000) Comparative column elution of jarosite waste and its autoclaved product-evidence for the immobilization of deleterious elements in jarosite. Minerals Engineering 13(3):287-296

[4] Han H, Sun W, Hu Y, Jia B, Tang H (2014) Anglesite and silver recovery from jarosite residues through roasting and sulfidization-flotation in zinc hydrometallurgy. Journal of Hazardous Materials 278:49-54

[5] Pappu A, Saxena M, Asolekar SR (2006) Jarosite characteristics and its utilisation potentials. Science of the Total Environment 359:232-243

[6] Wegscheider S, Steinlechner S (2016) Residues from the zinc industry - a potential future resource for silver and indium. In: Proceedings of IMPC 2016: XXVIII International Mineral Processing Congress, Canada

[7] Wood J, Coveney J, Helin G, Xu L, Xincheng S (2015) The Outotec ${ }^{\circledR}$ Direct Zinc Smelting Process. In: Proceedings of EMC 2015: European Metallurgical Conference, Germany

[8] Toropainen A (2016) A computational thermodynamic model for conversion of jarosite residue into an inert slag via a pyrometallurgical process. Master's thesis, Aalto University

[9] Davies R, Dinsdale A, Gisby J, Robinson J, Martin S (2002) MTDATA-thermodynamic and phase equilibrium software from the national physical laboratory. Calphad 26(2):229-271

[10] Gisby J, Taskinen P, Pihlasalo J, Li Z, Tyrer M, Pearce J, Avarmaa K, Björklund P, Davies H, Korpi M, Martin S, Pesonen L, Robinson J (2017) MTDATA and the prediction of phase equilibria in oxide systems: 30 years of industrial collaboration. Metallurgical and Materials Transactions B 48(1):91-98

[11] Choi CY, Lee YH (1999) Treatment of zinc residues by Ausmelt technology at Onsan zinc refinery. Presented at REWAS '99 - Global Symposium on Recycling Waste Treatment and Clean Technology, Spain

[12] Hoang J, Reuter MA, Matusewicz R, Hughes S, Piret N (2009) Top submerged lance direct zinc smelting. Minerals Engineering 22:742-751

[13] Lavrent'ev YG, Korolyuk VN, Usova LV (2004) Second Generation of Correction Methods in Electron Probe X-ray Microanalysis: Approximation Models for Emission Depth Distribution Functions. Journal of Analytical Chemistry 59(7):600-616

[14] Homma S, Ogata S, Koga J, Matsumoto S (2005) Gas-solid reaction model for a shrinking spherical particle with unreacted shrinking core. Chemical Engineering Science 60(18):4971-4980

[15] De Wilde E, Bellemans I, Kampforts M, Guo M, Blanpain B\& Moelans N, Verbeken K (2016) Investigation of High Temperature Slag/Copper/Spinel Interactions. Metallurgical and Materials Transactions B 47:1-14 